\title{
IN VITRO SCREENING FOR ANTICHOLINESTERASE AND ANTIOXIDANT ACTIVITY OF EXTRACT OF GARCINIA ATROVIRIDIS
}

\author{
CHITRA V*, NARAYANAN J \\ Department of Pharmacology, SRM College of Pharmacy, SRM Institute of Science and Technology, Kattankulathur, Kanchipuram, Tamil \\ Nadu, India. Email: velchitram74@gmail.com
}

Received: 22 March 2018, Revised and Accepted: 21 May 2018

\begin{abstract}
Objective: Garcinia atroviridis belongs to the family Clusiaceae. The whole plant was dried, extracted to obtain a xanthone-rich extract. Phytochemical studies of extract showed the presence of phenols, alkaloids, steroids, resins, and saponins. Alzheimer's disease (AD) the most common form of dementia, a brain disorder which has been affecting the elderly. The natural sources such as plants are an abundant source having various medicinal properties.
\end{abstract}

Methods: In the present study, G. atroviridis has been selected to test for the acetylcholinesterase (AChE) and butyrylcholinesterase (BuChE) activity by Ellman's method. The antioxidant activity has been performed by 2,2'-diphenyl-1-picrylhydrazyl radical (DPPH) assay.

Results: The results showed that the extract from G. atroviridis could inhibit the activity of AchE and BuChE. The percentage inhibition of the ethanolic extract for AChE was found to be $69.4 \%$, and ethyl acetate extract was found to be $75.6 \%$, respectively. The percentage inhibition of the ethanolic extract for BuChE was found to be $59.4 \%$, and ethyl acetate extract was found to be $63.2 \%$, respectively. The IC50 values for DPPH scavenging activity were significant when compared with the standard ascorbic acid.

Conclusion: The plant extract with significant antioxidant and anticholinesterase property has shown its potential to be investigated further as a therapeutic drug for AD.

Keywords: Garciniaatroviridis, Xanthones, Anticholinesterase, Antioxidant, Alzheimer's disease, Oxidative stress.

(C) 2018 The Authors. Published by Innovare Academic Sciences Pvt Ltd. This is an open access article under the CC BY license (http://creativecommons. org/licenses/by/4. 0/) DOI: http://dx.doi.org/10.22159/ajpcr.2018.v11i9.24934

\section{INTRODUCTION}

Alzheimer's disease (AD) is a slow progressive disease which is characterized by neurodegeneration. The degeneration is caused in the cortex and the limbic system along with the presence of the $A \beta$ and neurofibrillary tangles. Various studies which have been conducted supports the cholinergic hypothesis, in which it explains that the dysfunction of the cholinergic system is the reason for the memory deficits and the cognitive decline seen in animals which are found to be in similarity with dementia caused in AD. These models indicate the characteristic degeneration of cholinergic neurons in the brain. The two major forms of cholinesterases are present. They are acetylcholinesterase (AChE) and butyrylcholinesterase (BuChE) [1]. These also produce a marked decline in the cholinergic markers, choline acetyltransferase, and acetylcholinesterase [2].

The neuropathology of the brain present during AD cannot be completely explained by the presence of cholinergic deficits. However, the marked evidence seen with the cholinergic neuron degeneration shows an avenue of exploration for the treatment of AD symptoms [3]. $\mathrm{AD}$ patients were found to have reduced levels of Ach in the cortex and the hippocampal region. The current approach which has been found to provide symptomatic relief is the utilization of cholinesterase inhibitors which causes inhibition of AChE which leads to the hydrolysis of ACh at the cholinergic synapse [4].

Oxidative stress plays a major role as a risk factor in various diseases. The oxidative stress is due to the presence of free radicals leading toward degeneration of neurons in case of idiopathic AD. The reactive oxygen species and reactive nitrogen species are generated extracellularly and intracellularly. The brain consumption of oxygen increases leading to the presence of high-lipid content and along with the decline of antioxidant compounds causes it to be more vulnerable to oxidative stress when compared with other tissues [5]

In brains of $\mathrm{AD}$ patients, there also been evidence for the presence of advanced glycation end-products, markers of peroxidation, increased levels of oxidized protein and 4-hydroxynonenal (4HNE). The presence of amyloid beta causes the lipoperoxidation of the membranes, and the lipid peroxidation products lead to protein modification [6]. The peroxidation process forms an aldehyde product which is 4-HNE. The generation of this due to the exposure of the neuronal membranes to the amyloid beta peptide. Further, oxidative damage is caused by this process with an increase in the carbonyl groups [7].

The aim of this study is to investigate the presence of AChE or BuChE inhibitors in Garcinia atroviridis [8]. The ethyl acetate extract of the plant was taken because of the presence of xanthones. The extract was then evaluated for its for its AChE, BuChE, and antioxidant activity to screen them for its efficacy in treating AD.

\section{MATERIALS AND METHODS}

2,2'-diphenyl-1-picrylhydrazyl radical (DPPH), acetylthiocholine iodide, AChE, bovine serum albumin, 5, 5'-dithiobis [2-nitrobenzoic acid] (DTNB), physostigmine, gallic acid, and ascorbic acid. All the other reagents are of analytical grade.

\section{Plant materials}

The plant materials were procured from Rajesh Chemicals, Mumbai. It is authenticated by Prof. P. Jayaraman, Plant Anatomy Research Center, Tambaram. The registration number of the certificate is PARC/2017/3578. 
Preparation of extract of $G$. atroviridis

Extracts were prepared by the maceration method at $60^{\circ} \mathrm{C}$ for $72 \mathrm{~h}$ using ethanol $70 \%$ and ethyl acetate. The extracted samples were evaporated using a water bath. The thick extract obtained is made into various concentrations for the study $(5,25,100$, and $200 \mu \mathrm{g} / \mathrm{l})$.

\section{Preliminary phytochemical analysis}

The plant extract was used for preliminary screening of active constituents such as phenols, alkaloids, steroids, resins, proteins, carbohydrates, and saponins [9]. The phytochemical analysis was performed using the standard procedures to investigate the constituents present in the plant $[10,11]$

Determination of antioxidant activity by scavenging effect on DPPH The antioxidant potential of the ethyl acetate extract was estimated using modified DPPH free radical scavenging assay. The stock solution of the ethyl acetate extracts was prepared in $1 \mathrm{mg} / \mathrm{ml}$ in methanol. Each well was filled in with $200 \mu \mathrm{l}$ extract in methanol at $1000 \mu \mathrm{g} / \mathrm{ml}$

Then, $5 \mu \mathrm{l}$ of the DPPH solution $(2.5 \mathrm{mg} / \mathrm{ml}$ in methanol) was added to each well. The plate is allowed to develop in the dark for $30 \mathrm{~min}$. The optical density of the plate was read using a microplate reader at $517 \mathrm{~nm}$. Percentage inhibition was calculated using:

$\%$ Inhibition $=1$ OD $(\mathrm{DPPH}+$ Sample $) / \mathrm{OD}(\mathrm{DPPH}) \times 100$

The percentage inhibition of free radical activity was plotted against the concentration of the ethyl acetate extract, and IC50 concentration for $50 \%$ inhibition was obtained. The percentage inhibition was compared with ascorbic acid which was the positive control $[12,13]$.

Determination of $\mathrm{AChE}$ and butyrylcholinesterase inhibitory activity using microplate assay

AChE activity was measured using a modified 96-well microplate assay which is based on the Ellman's method [12,13]. In this assay, the enzyme hydrolyzes the acetylthiocholine or butyrylthiocholine resulting in the formation of thiocholine on its reaction with Ellman's reagent (DTNB) produces 2-nitrobenzoate-5-mercapto thiocholine and 5-thio-2-nitrobenzoate which is detected at $412 \mathrm{~nm}$ [14]

The reaction volume is made of $220 \mu \mathrm{l}$ which comprises $170 \mu \mathrm{l}$ $(0.1 \mathrm{~mol} / \mathrm{l})$ sodium phosphate buffer, $10 \mu \mathrm{l}$ of the extract solution, $10 \mu \mathrm{l}$ DTNB, $20 \mathrm{ul}$ of AChE/BuChE $(0.45 \mathrm{U} / \mathrm{ml})$, and $10 \mu \mathrm{l}$ of acetylthiocholine iodide/butyrylthiocholine iodide (concentration $0.68 \mathrm{mmol} / \mathrm{l}$ )

The methanolic and ethanolic extracts were tested for the BuChE and AChE inhibitory activity from concentrations 5, 25, 100, and $200 \mu \mathrm{g} / \mathrm{ml}$, respectively. They are prepared using phosphate buffer. Galanthamine was used a positive control with the same concentrations. The buffer, extract, and enzyme were incubated $15 \mathrm{~min}$ at $40^{\circ} \mathrm{C}$. The reaction is initiated by the addition DTNB and substrate. It is incubated at $25^{\circ} \mathrm{C}$ for $30 \mathrm{~min}$, and absorbance is read at $405 \mathrm{~nm}$. The blank consists of a buffer and enzyme without the test extracts. The percentage inhibition is calculated using the following formula:

$\%$ inhibition $=(\mathrm{E} \mathrm{S}) / \mathrm{E} \times 100$

$\mathrm{E}=$ Activity of enzyme without extract

$\mathrm{S}=$ Activity of enzyme with extract

IC50 was calculated from the $\%$ inhibition values of the plant extract.

\section{Statistical analysis}

Data were expressed as mean \pm standard deviation for separate groups for determinations in triplicates. IC50 values were calculated using GraphPad Prism v 5.0 (GraphPad Software Inc., USA)

\section{RESULTS}

Free Radical Scavenging Activity of the Extracts using the DPPH Assay The anti-oxidant activity of the ethyl acetate fractions was determined by using free radical 1,1-diphenyl-2- picrylhydrazyl (DPPH) performed by the addition of various concentrations of extracts with DPPH. The DPPH amount which is remaining was determined at 30 minutes based on the absorbance at $517 \mathrm{~nm}$. IC50 values for DPPH scavenging activity was calculated for concentrations of the extract. The IC50 values are shown in Table 2 [15]. The IC50 values of the ethanolic extract was found to be 19.78 and for Ethyl acetate extract 13.38 [Fig. 1]. It exhibited good activity for DPPH scavenging when compared with that of the standard Ascorbic acid with an IC50 value of 4.28. [16,17]

\section{Acetylcholinesterase and Butyrylcholinesterase Inhibitory} Activity of the Extracts

The ethyl acetate fraction has been utilized for AChE inhibitory activity using Ellman's colorimetric assay using 96 well plate. [18,19] Results are shown in Table 1. Galanthamine was used as the standard AChE inhibitor in this study which showed a \% inhibition of AChE at 87.6\%. [20]

The percentage inhibition of the e extract for BuChE was found to be $59.4 \%$ and Ethylacetate extract was found to be $63.2 \%$ respectively [Fig. 2].

The percentage inhibition of the Ethanolic extract for AChE was found to be $69.4 \%$ and Ethylacetate extract was found to be $75.6 \%$ respectively [Fig. 3].

\section{DISCUSSION}

Deficits seen in the levels of acetylcholine is one of the contributing factors seen in AD such as memory impairment and cognitive decline. As a characteristic feature seen in $\mathrm{AD}$, there is a reduction in the levels of acetylcholine and butyrylcholine. Treatment of the disease includes rivastigmine, donepezil, galanthamine, etc. which can be used for the cholinergic decline. The AChE inhibitors which are utilized for the treatment include side effects such as tolerability, toxicity, and loss of efficiency. These unwanted effects along with the low efficacy of the drugs make the treatment to be questionable. Therefore, drugs from natural sources are well worthy of their investigation [21].

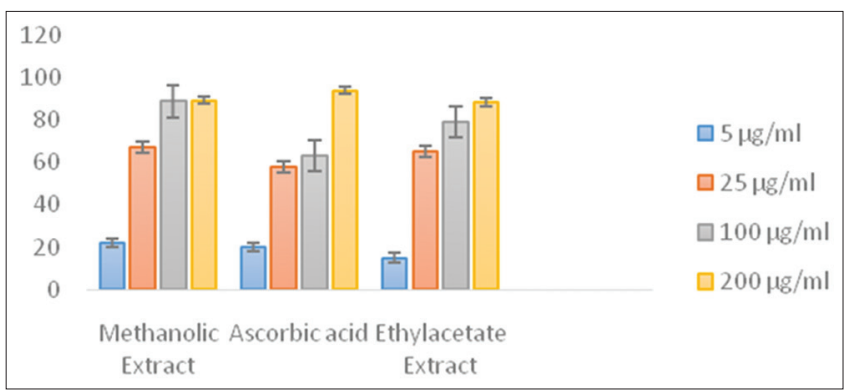

Fig. 1: Determination of antioxidant activity by 2,2'-diphenyl-1picrylhydrazyl radical assay

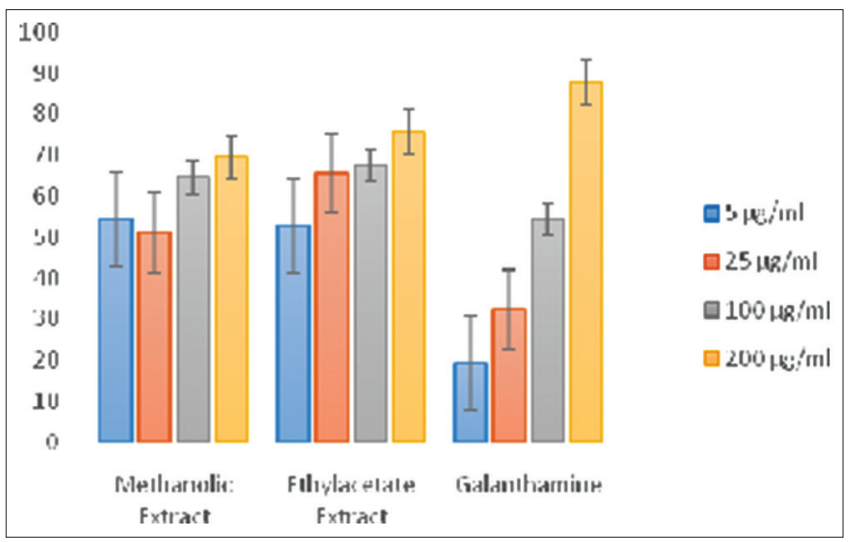

Fig. 2: Determination of acetylcholinesterase inhibition by Ellman's method 
Table 1: Determination of antioxidant activity by DPPH assay

\begin{tabular}{|c|c|c|c|c|}
\hline Method & Sample & Concentration $(\mu \mathrm{g} / \mathrm{ml})$ & Activity (\%) & IC50 \\
\hline \multirow[t]{15}{*}{ DPPH } & Methanolic extract & 5 & 22.12 & $19.780^{*}$ \\
\hline & & 25 & 67.14 & \\
\hline & & 100 & 88.74 & \\
\hline & & 200 & 89.11 & \\
\hline & Ascorbic acid & 5 & 20.14 & 19.526 \\
\hline & & 25 & 57.78 & \\
\hline & & 100 & 63.22 & \\
\hline & Ethyl acetate extract & 5 & 14.9 & $13.388^{* *}$ \\
\hline & & 25 & 65.24 & \\
\hline & & 100 & 79.14 & \\
\hline & & 200 & 88.40 & \\
\hline & Ascorbic acid & 5 & 21.16 & 4.280 \\
\hline & & 25 & 77.68 & \\
\hline & & 100 & 80.22 & \\
\hline & & 200 & 81.91 & \\
\hline
\end{tabular}

Values are mean $\pm \mathrm{SD}(\mathrm{n}=3) .{ }^{* *} \mathrm{p}<0.01$ versus control, ${ }^{*} P<0.05$ versus galanthamine. One way ANOVA followed by Tukey's test. SD: Standard deviation, DPPH: 2,2'-diphenyl-1-picrylhydrazyl radical

Table 2: Determination of AChE and BuChE inhibition by Ellman's method

\begin{tabular}{|c|c|c|c|}
\hline Treatment & Concentration $(\mu \mathrm{g} / \mathrm{ml})$ & $\%$ BuChE inhibition & $\% A C h E$ inhibition \\
\hline \multirow[t]{4}{*}{ Methanolic extract } & 5 & $11.4 \pm 0.4$ & $54.5 \pm 2.0$ \\
\hline & 25 & $18.3 \pm 0.3$ & $51.2 \pm 2.7$ \\
\hline & 100 & $22.4 \pm 0.4$ & $64.5 \pm 9.2$ \\
\hline & 200 & $59.7 \pm 0.1$ & $69.4 \pm 9.3^{*}$ \\
\hline \multirow[t]{3}{*}{ Ethyl acetate extract } & 5 & $3.0 \pm 0.1$ & $52.8 \pm 0.9$ \\
\hline & 25 & $18.6 \pm 0.5$ & $65.7 \pm 3.6$ \\
\hline & 100 & $60.80 \pm 3.5^{*}$ & $67.4 \pm 4.1^{*}$ \\
\hline \multirow[t]{4}{*}{ Galanthamine } & 5 & 17.1 & 19.4 \\
\hline & 25 & 28.1 & 32.2 \\
\hline & 100 & 34.3 & 54.3 \\
\hline & 200 & 42.3 & 87.6 \\
\hline
\end{tabular}

Values are mean $\pm \mathrm{SD}(\mathrm{n}=3){ }^{* *} \mathrm{p}<0.01$ versus control, ${ }^{*} \mathrm{p}<0.05$ versus galanthamine. One way ANOVA followed by Tukey's test. SD: Standard deviation, AChE: Acetylcholinesterase, BuChE: Butyrylcholinesterase

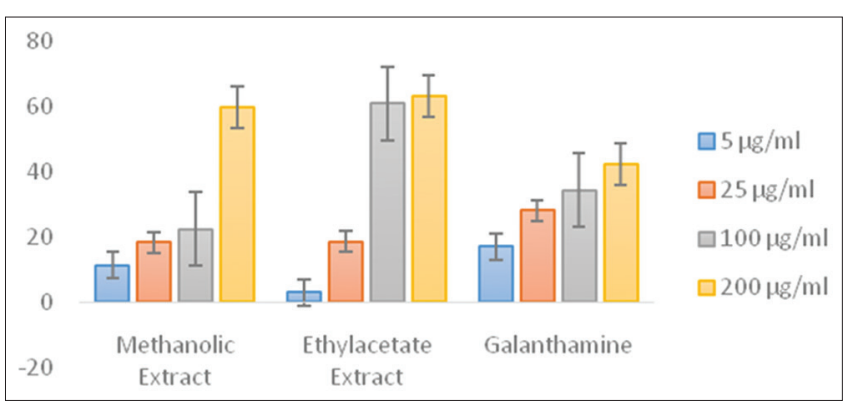

Fig. 3: Determination of butyrylcholinesterase inhibition by Ellman's method

The current study utilized the ethanolic and ethyl acetate extract of the plant $G$. atroviridis. It has been selected based on the presence of xanthones. Xanthones being an important phytoconstituent for which the pharmacological actions have been a point of investigation in the recent times. G. atroviridis containing xanthones has been proven to have various pharmacological actions such as anti-inflammatory, anticancer, etc. $[22,23]$. G.hanburyi contains various phytoconstituents such as Xanthones, Flavonoids, polyphenols etc which may consists of anti-oxidants. These antioxidants can counter free radical damage produced during metabolism and also the radical levels may be increased in Alzheimer's disease [24]. Since these extracts contain a variety of phytochemical constituents, they contain secondary metabolites which can interact for the biological activity. The activity which has been demonstrated by the extract may be due to the presence of xanthones which are the major dominant constituent.

\section{CONCLUSION}

The various biological activities which were examined in the present study such as anti-oxidant, anti-AChE and BuChE property for the plant Garcinia atroviridis. These activities which were examined in the present study warrants further investigation. The results which have been obtained has indicated that the anti-oxidant activity and inhibition of acetylcholine esterase and butyrylcholinesterase can make them to be evaluated as an effective, new therapeutic agent for the treatment of Alzheimer's disease. The extract which is analyzed can be further investigated either as a single isolated compound or as an extract to be used as a therapeutic agent.

\section{ACKNOWLEDGMENTS}

The authors are grateful for the management of SRM Institute of Science and Technology for providing financial support and facilities. The authors are grateful for SRM College of Pharmacy, SRM Institute of Science and Technology for supporting this study.

\section{AUTHORS CONTRIBUTION}

Both the authors contributed equally to the work. The study design was conducted by Dr. V. Chitra with her expertise in neuroscience. Mr. J. Narayanan was responsible for the evaluation and the statistical analysis of the parameters.

\section{CONFLICTS OF INTEREST}

The authors declare that there are no conflict of interest. 


\section{REFERENCES}

1. de Leon MJ, Golomb J, George AE, Convit A, Tarshish CY, McRae T, et al. The radiologic prediction of Alzheimer disease: The atrophic hippocampal formation. AJNR Am J Neuroradiol 1993;14:897-906.

2. Blennow K, de Leon MJ, Zetterberg H. Alzheimer's disease. Lancet 2006;368:387-403.

3. Auld DS, Kornecook TJ, Bastianetto S, Quirion R. Alzheimer's disease and the basal fore brain cholinergic system: Relations to b-amyloid peptides, cognition and treatment strategies. Prog Neurobiol 2002;68:209-45.

4. Bowen DM, Palmer AM, Frances PT, Procter AW, Lowe SL. Classical neurotransmitters in Alzheimer's disease. In: Terry RD, editro. Aging and the Brain. New York: Raven Press; 1988. p. 115-28.

5. Multhaup G, Ruppert T, Schlicksupp A, Hesse L, Beher D, Masters CL, et al. Reactive oxygen species and Alzheimer's disease. Biochem Pharmacol 1997;54:533-9.

6. Perry G, Taddeo MA, Nunomura A, Zhu X, Zenteno-Savin T, Drew KL, et al. Comparative biology and pathology of oxidative stress in Alzheimer and other neurodegenerative diseases: Beyond damage and response. Comp Biochem Physiol (C) 2002;133:507-13

7. Prasad KN, Hovland AR, Cole WC, Prasad KC, Nahreini P, Edwards-Prasad J, et al. Multiple antioxidants in the prevention and treatment of Alzheimer disease: Analysis of biological rationale. Clin Neuropharmacol 2000;23:2-13.

8. FAO. Under-Utilized Tropical Fruits of Thailand, RAP Publication 2001/26 Publication. Suranant Subhadrabandhu. Bangkok, The United Nations: FAO; 2001.

9. Harborne JB. Phytochemical Methods. London: Chapman and Hall Ltd.; 1992. p. 7-8.

10. Roy A, Geetha RV. Preliminary phytochemical screening of the ethanolic extract of Dioscorea villosa tuber and estimation of Diosgenin by HPLTC technique. Int J Drug Dev Res 2013;5:377-81.

11. Al-Massarani SM, El Gamal AA, Al-Musayeib NM, Mothana RA, Basudan OA, Al-Rehaily AJ, et al. Phytochemical, antimicrobial and antiprotozoal evaluation of Garcinia mangostana pericarp and alpha mangostin, its major xanthone derivative. Molecules 2013;18:10599-608

12. Subhashini N, Nagarajan G, Kavimani S. In vitro antioxidant and anticholinesterase activities of Garcinia cambogia. Int J Pharm Pharm Sci 2011;3:12932
13. Kukkar MR, Saluja AK, Sachdeva PD, Kukkar RR. In vivo investigation of the neuroprotective potential of Cardiospermum halicacabum Linn. Int J Pharm Pharm Sci 2014;6:64-6.

14. Kosem N, Han YH, Moongkarndi P. Antioxidant and cytoprotective activities of methanolic extract from Garcinia mangostana hulls. Sci Asia 2007;33:283-92.

15. Hernandez MF, Falé PL, Araújo ME, Serralheiro ML. Acetylcholinesterase inhibition and antioxidant activity of the water extracts of several Hypericum species. Food Chem 2010;120:1076-82.

16. Politeo O, Botica I, Bilusić T, Jukić M, Carev I, Burcul F, et al. Chemical composition and evaluation of acetylcholinesterase inhibition and antioxidant activity of essential oil from Dalmatian endemic species pinusnigra arnold ssp. dalmatica (Vis.) Franco. J Med Plants Res 2011;5:6590-6.

17. Savelev SU, Okello EJ, Perry EK. Butyryl-and acetyl-cholinesterase inhibitory activities in essential oils of Salvia species and their constituents. Phytother Res 2004;18:315-24.

18. Shimada K, Fujikawa K, Yahara K, Nakamura T. Antioxidative properties of xanthones on the auto-oxidation of soybean oil in cyclodextrin emulsion. J Agric Food Chem 1992;40:945-8.

19. Lee BW, Lee JW, Lee ST, Lee HS, Lee WS, Jeong TS, et al. Antioxidant and cytotoxic activities of xanthones from Cudrania tricuspidata. Bioorg Med Chem Lett 2005; 15:5548-52.

20. Zheleva-Dimitrova D, Balabanova V. Antioxidant and acetylcholinesterase inhibitory potential of Arnica montana cultivated in Bulgaria. Turk J Biol 2012;36:732-7.

21. Talić S, Dragičević I, Ćorajević L, Bevanda AM. Acetylcholinesterase and butyrylcholinesterase inhibitory activity of extracts from medicinal plants. Bull Chem Technol Bosnia Herzegovina 2014;43:11-4.

22. Ellman GL, Courtney KD, Andres V, Featherstone RM. A new and rapid colorimetric determination of acetylcholinesterase activity. Biochem Pharmacol 1961;7:88-95.

23. Adsersen A, Gauguin B, Gudiksen L, Jager AK. Screening of plants used in Danish folk medicine to treat memory dysfunction for acetylcholinesterase inhibitory activity. J Ethnopharmacol 2006;104:418-22.

24. Finkel T, Holbrook NJ. Oxidants, oxidative stress and the biology of aging. Nature 2002;408:239-47. 